\title{
INDIVÍDUO, SOCIEDADE E DIREITOS HUMANOS: A SUSTENTABILIDADE INTEGRADA À IDEIA DE BEM VIVER E SUA RELAÇ̃̃O COM OS NEGÓCIOS JURÍDICOS NO MUNDO GLOBALIZADO
}

$\frac{\text { Miguel Etinger de Araujo Junior }^{1}}{\text { Universidade Estadual de Londrina (UEL) }}$

Luiz Gustavo Campana Martins ${ }^{2}$

Universidade Estadual de Londrina (UEL)

\section{RESUMO}

Este trabalho tem por intuito discutir a ressignificação do conceito de sustentabilidade para que ele possa responder às crises socioambientais do Estado Moderno, contribuindo, assim, para o fortalecimento dos negócios jurídicos, no âmbito do direito negocial, respeitando a proteção ao meio ambiente. O problema enfrentado é que o conceito de sustentabilidade em sua atual configuração não tem respondido, de forma satisfatória, às crises e aos problemas contemporâneos. Com isso, busca-se averiguar, sob a perspectiva da escola ambiental crítica, se a integração da ideia de bem viver à sustentabilidade, no contexto do Estado Socioambiental, pode contribuir para revigorar o conceito, a fim de que ele possa fazer frente aos novos poderes transnacionais que resultam do mundo capitalista globalizado. Quanto à metodologia, a pesquisa se caracteriza como bibliográfica e exploratória, uma vez que pretende fazer uma discussão, a partir de obras já publicadas, para melhor compreensão do tema. Espera-se, ainda, com o resultado, que possa ser utilizado para fundamentar práticas sociais concretas como conscientização crítica, utilização do novo conceito e fundamentação para novos estudos.

Palavras-chave: bem viver; Direito Negocial; Estado Socioambiental; globalização; sustentabilidade.

1 Doutor em Direito da Cidade pela Univeridade do Estado do Rio de Janeiro (UERJ). Mestre em Direito pela Universidade Estácio de Sá (UNESA). Graduado em Direito pela UERJ. Professor adjunto da UEL nos cursos de Graduação e Mestrado em Direito. Procurador Jurídico da UEL. E-mail: miguel.etinger@gmail.com

2 Mestrando em Direito Negocial pela UEL. Bolsista CAPES. Especialista em Filosofia Política e Jurídica pela UEL. E-mail: gus.campana@hotmail.com. 


\section{INDIVIDUAL, SOCIETY AND HUMAN RIGHTS: SUSTAINABILITY INTEGRATED TO THE IDEA OF WELL LIVING AND ITS RELATIONSHIP WITH LEGAL BUSINESS IN THE GLOBALIZED WORLD}

\section{ABSTRACT}

The purpose of this paper is to discuss the re-signification of the concept of sustainability so that it can respond to the socio-environmental crises of the Modern State, thus contributing to the strengthening of legal business, within the scope of business law, respecting the protection of the environment. The problem faced is that the concept of sustainability in its current configuration has not responded satisfactorily to crises and contemporary problems. The aim of this study is to examine, from the perspective of the critical environmental school, if the integration of the idea of living well into sustainability in the context of the Socio-environmental State can contribute to reinvigorate the concept so that it can cope with the new transnational powers that result from the globalized capitalist world. As for the methodology, the research is characterized as bibliographic and exploratory, since it intends to make a discussion, from works already published, for a better understanding of the theme. It is hoped, with the result, that it can be used to support concrete social practices such as critical awareness, use of the new concept and justification for new studies.

Keywords: Business Law; globalization; Socio-environmental State; sustainability; well live. 


\section{INTRODUÇÃO}

De início, tendo em vista o tema a ser discutido, no âmbito do direito negocial, são necessárias algumas considerações preliminares a fim de demarcar o desenvolvimento deste artigo. Para isso, entende-se o direito negocial como um ramo específico do direito responsável pela interpretação, regulação e direcionamento dos negócios jurídicos, que são manifestações de vontade aptas a gerar efeitos jurídicos.

É fundamental, ainda, pontuar-se o art. 170 da Constituição Federal de 1988, que simboliza um marco do trabalho humano e da livre iniciativa. Ao amarrar a aliança que existe entre a ordem econômica e a democracia, o art. 170 constitui o ponto de partida inicial deste trabalho: o olhar humanista, democrático e de justiça social sobre a racionalidade econômica. Portanto, parte-se da ideia de que as relações comerciais de troca, compra e venda, os próprios negócios jurídicos, no mundo capitalista globalizado, têm relação - e não podem se desvencilhar - com a construção do Estado Democrático de Direito.

Nesse sentido, com auxílio de Eros Grau (2010), interpreta-se que a ordem econômica constitui um conjunto de normas programáticas em uma constituição dirigente, ou seja, são normas que visam os fins e os objetivos de um Estado Social, não devendo serem elas vistas de forma isolada ou deslocadas de todo o ordenamento constitucional. Assim, o art. 170 e seguintes devem ser interpretados sob o olhar da justiça e função social da propriedade e dos contratos, estando em sintonia com os fundamentos e objetivos da república, a exemplo da dignidade da pessoa humana e da construção de uma sociedade livre, justa e solidária, como estipulados nos arts. $1^{\circ}$ e $3^{\circ}$ da CF/88 (BRASIL, 1988).

Não menos importante, em verdade, essencial, é a interpretação integrativa que se deve ter, também, da ordem econômica com o art. 225, da $\mathrm{CF} / 88$, que promove a defesa ao meio ambiente aliada à sadia qualidade de vida e à sustentabilidade. Explica o professor Eros Grau (2010, p. 256) que:

O princípio da defesa do meio ambiente conforma a ordem econômica (mundo do ser), informando substancialmente os princípios da garantia do desenvolvimento e do pleno emprego. Além de objetivo, em si, é instrumento necessário - e indispensável - à realização do fim dessa ordem, o de assegurar a todos existência digna. Nutre também, ademais, os ditames da justiça social. Todos têm direito ao meio ambiente ecologicamente equilibrado, bem de uso comum do povo - diz o art. 225, caput. 
Assim, no atual Estado capitalista moderno, é imprescindível pensar a efetiva proteção do meio ambiente como um fim em si e, também, como necessário à realização da ordem econômica. Hoje, a realização dos negócios jurídicos, através da atuação das empresas, deve se pautar por princípios de sustentabilidade social e ambiental. Essa interpretação, conquistada ao longo de séculos e à custa de muitas vidas, deve ser mantida e somente alterada para sua ampliação e melhoramento de direitos.

Segundo Canotilho (2003), o princípio do não retrocesso social institui uma espécie de proteção às normas constitucionais de direitos sociais e econômicos contra políticas e interesses de governos transitórios. Por esse viés, o princípio do não retrocesso confere uma aura de proteção ao atribuir status de política de Estado à ordem constitucional econômica e social. Afirma também, que ao gerar essa garantia institucional e um direito subjetivo, limita-se a atuação do legislador e dos governos provisórios, exigindo uma atuação política permanente, condizente com essas garantias, de forma que se torna inconstitucional qualquer medida que prejudique o núcleo essencial desses direitos.

Com a instituição do princípio de não retrocesso social, nas palavras do próprio professor José Gomes Canotilho (2003, p. 338):

[...] quer dizer-se que os direitos sociais e económicos (ex.: direito dos trabalhadores, direito à assistência, direito à educação), uma vez obtido um determinado grau de realização, passam a constituir, simultaneamente, uma garantia institucional e um direito subjectivo. A "proibição de retrocesso social" nada pode fazer contra as recessões e crises económicas (reversibilidade fática), mas o princípio em análise limita a reversibilidade dos direitos adquiridos (ex.: segurança social, subsídio de desemprego, prestações de saúde), em clara violação do princípio da protecção da confiança e da segurança dos cidadãos no âmbito económico, social e cultural, e do núcleo essencial da existência mínima inerente ao respeito pela dignidade da pessoa humana.

O reforço e a discussão dessa posição, que se demonstra no decorrer deste artigo, são fundamentais tendo em vista as frentes e os poderes capitalistas transnacionais que afrontam diretamente os interesses socioambientais - na busca pela construção de uma sociedade mais justa, equilibrada e sustentável.

Em justa crítica, contrário à interpretação individualista de negócio jurídico, Edson Fachin (2012, p. 277) infere que:

A autonomia privada, vista como um dogma, está teoricamente ultrapassada. Permanece, todavia, a indagação sobre o que colocar no lugar de seu conceito, 
no âmbito dos contratos. Depreende-se, então, a necessidade de nova proposta de reflexão transdisciplinar, para que se possa compreender melhor esse momento. $\mathrm{O}$ estabelecimento de uma espécie de cartografia da transdisciplinaridade impõe em repensar do sujeito e do objeto, bem como da metodologia da investigação científica, voltada para esses estatutos jurídicos fundamentais.

Por derradeiro, acrescenta-se que este artigo adota em sentido amplo a noção de negócio jurídico e de meio ambiente, às quais o ser humano se integra, bem como também adota a sustentabilidade como conceito basilar que promove o encontro entre o indivíduo, a sociedade e os direitos humanos, sob o enfoque do direito negocial no atual mundo globalizado.

Assim, os próximos capítulo tratarão, nessa ordem, (1) da construção histórica e do posicionamento deste trabalho a respeito do conceito de sustentabilidade, (2) da crise do Estado Nacional, no contexto do mundo globalizado, (3) da integração da ideia de bem viver ao conceito de sustentabilidade, em um estado socioambiental, e, por fim, (4) das considerações finais acerca das reflexões deste trabalho.

\section{ABORDAGEM CRÍTICA E HISTÓRICO-FILOSÓFICA DA SUSTENTABILIDADE}

A partir da conferência de Estocolmo, em 1972, as discussões em torno de um desenvolvimento econômico em consonância com a preservação do meio ambiente ganharam força. Desde então, algumas políticas e conceitos foram amadurecendo juntamente com uma consciência coletiva mundial. $\mathrm{O}$ conceito de sustentabilidade - derivado de desenvolvimento sustentável -, originado do Relatório Brundtland, em $1987^{3}$, representa um marco na história ambiental global, já tendo passado por algumas transformações.

Há outro marco, nesse sentido, como a criação do Triple Bottom Line $e^{4}$, um instrumento que mede os resultados sustentáveis de uma empresa em

3 O Relatório Brundtland é o resultado de estudos que se sucederam à Conferência Mundial sobre o Homem e o Meio Ambiente em Estocolmo, Suécia, em 1972.

4 "A frase "the triple bottom line" foi cunhada pela primeira vez em 1994 por John Elkington, o fundador de uma consultoria britânica chamada SustainAbility. Seu argumento era que as empresas deveriam estar preparando três linhas de base diferentes (e bastante separadas). Uma é a medida tradicional do lucro corporativo - o "resultado final" da conta de lucros e perdas. A segunda é a linha de fundo da "conta de pessoas" de uma empresa - uma medida de alguma forma ou forma de como uma organização socialmente responsável tem sido durante suas operações. A terceira é a linha de fundo da conta "planetária" da empresa - uma medida de quão ambientalmente responsável ela tem sido. O triple bottom line (TBL) consiste, portanto, em três Ps: profit, people e planet. Tem como objetivo medir o desempenho financeiro, social e ambiental da corporação durante um período de tempo. Somente uma empresa que produz um TBL está levando em conta o custo total envolvido em fazer negócios" (TRIPLE..., 2009, tradução nossa). 
termos sociais, ambientais e econômicos. A expressão, criada por John Elkington (1994), auxilia a compreensão de que as empresas devem contribuir para a sustentabilidade. Nesse viés, as práticas sustentáveis vêm sendo cada vez mais valorizadas pelo mercado de consumidores, uma vez que a conscientização populacional está aumentando e provocando um interesse maior dos setores coorporativos em atenderem às expectativas socioambientais.

Hoje, a ideia de garantir os meios e as necessidade das gerações presentes e futuras encontra-se ultrapassada segundo alguns autores. Já em 1996, em um artigo escrito para o jornal de políticas públicas da universidade de Cambridge, Dovers fazia uma crítica a esse conceito dizendo que lhe faltava clareza e trazia, então, uma importante diferenciação conceitual entre sustentabilidade e desenvolvimento sustentável:

Sustainabilitiy is the ability of a natural, human or mixed system to withstand or adapt to, over an indefinite time scale, endogenous or exogenous changes perceived as threatening. Sustainable development is a pathway of deliberate endogenous change (improvement) that maintains or enhances this attribute to some degree, while answering the needs of the present population (DOVERS, 1996, p. 304). ${ }^{5}$

A partir desse entendimento, nota-se que a sustentabilidade está ligada à capacidade de resistência ou adaptação de um sistema, natural ou humano, às mudanças que o ameaçam, ou seja, no mesmo sentido de capacidade de suporte da pegada ecológica ${ }^{6}$.

A doutrina ambiental moderna tem avaliado o conceito de sustentabilidade sob o ponto de vista da escola ambiental crítica, da ecologia política e da justiça ambiental, que formam, segundo Loureiro e Layrargues (2013), uma aliança contra-hegemônica na busca pela superação das relações sociais alienantes destrutivas da natureza.

Os autores definem a escola ambiental tradicional por ser hegemônica, possuir uma visão mecanicista da ciência, além de não querer revelar as relações de poder estruturantes da sociedade (LOUREIRO; LAYRARGUES, 2013).

5 Nota de tradução: Sustentabilidade é a capacidade de um sistema natural, humano ou misto de suportar ou adaptar-se, em uma escala de tempo indefinida, a mudanças endógenas ou exógenas percebidas como ameaçadoras. O desenvolvimento sustentável é um caminho de mudança endógena deliberada (melhoria) que mantém ou aumenta esse atributo até certo ponto, enquanto responde às necessidades da população atual.

6 Segundo a ONG WWF-Brasil (World Wildlife Fund), “A Pegada Ecológica é uma metodologia de contabilidade ambiental que avalia a pressão do consumo das populações humanas sobre os recursos naturais. Expressada em hectares globais (gha), permite comparar diferentes padrões de consumo e verificar se estão dentro da capacidade ecológica do planeta. Um hectare global significa um hectare de produtividade média mundial para terras e águas produtivas em um ano" (WWF, 2018). 
Essa vertente, tradicional, é conservadora e funciona como mais um dos mecanismos de manutenção da lógica capitalista. Esse sistema exploratório se constitui e se adapta de acordo com as necessidades do mercado de cada época. Hoje, a necessidade que se impõe é a própria sustentabilidade e a proteção ao meio ambiente e, por isso, o setor empresarial tenta a todo momento reproduzir sua visão de sustentabilidade como hegemônica, uma falsa visão - segundo os adeptos da outra teoria - que busca apenas dar às pessoas a sensação de que o ecossistema está sendo protegido.

Por outro lado, a escola ambiental crítica, contra-hegemônica, é capaz de desvelar essas relações de dominação, explicitar as contradições da sociedade moderna, além de capacitar os indivíduos para uma formação social crítica, sendo fundamental para a superação da atual crise socioambiental.

Essas vertentes ambientais buscam ressignificar o conceito de sustentabilidade sob um viés crítico-social. No mesmo sentido, Ayala e Rodrigues (2013, p. 325) sustentam que

[...] o princípio da sustentabilidade deve passar por uma ressignificação, a fim de oferecer proteção não apenas a situações que tratem da integridade ecológica como meio para possibilitar a dignidade da vida humana, mas de modo a compreender o meio ambiente, em sua totalidade, como merecedor de proteção, pelo valor intrínseco que possui.

Busca-se, com isso, a partir da justiça e da equidade, redistribuir de maneira mais razoável as riquezas provenientes do mundo desenvolvido, a renda, bem como, por outro lado, redistribuir as mazelas provocadas pelo desenvolvimento econômico que, em geral, afetam apenas a população mais pobre: falta de saneamento básico, esgoto a céu aberto, lixões em áreas residenciais, desapropriações de bairros e vilarejos para construções de grandes impactos, entre outras.

O sociólogo Ulrich Beck (2010) constrói a tese da chamada sociedade do risco. Entende-se que essa característica social se refere à atual conjuntura moderna, onde a prevenção de riscos, a compensação econômica e a responsabilização pelos danos não são eficazes. É uma sociedade onde os instrumentos jurídicos e administrativos são incapazes de conferir uma justiça ambiental na distribuição dos danos e dos riscos sentidos pela população.

A justiça ambiental, segundo Iván López (2014), é um conceito amplo que possui na literatura jurídico-social uma série de críticas e definições.

Uma vez que não é intuito deste artigo debater os diferentes conceitos 
e divergências teóricas, pontua-se a definição aqui adotada de que a justiça ambiental diz respeito "aos princípios que asseguram que nenhum grupo de pessoas, sejam grupos étnicos, raciais ou de classe, suporte uma parcela desproporcional de degradação do espaço coletivo" (ACSELRAD; HERCULANO; PÁDUA, 2004, p. 10).

A justiça ambiental está relacionada à desigualdade socioambiental provocada pelas condições estruturais do capitalismo. Na sociedade do mercado livre, aqueles que dispõem de melhores condições econômicas podem estabelecer suas moradias em locais ambientalmente seguros, longe de quaisquer despejos, lixões, produtos tóxicos ou deteriorantes. Enquanto que os menos favorecidos sofrem de uma distribuição desigual das condições degradantes. São desigualdades políticas e de poder que, pelo viés crítico, são discutidas e ressignificadas (ACSELRAD, 2010).

A justiça ambiental, nesse viés, se aproxima da perspectiva crítica de sustentabilidade abordada neste artigo, sendo em boa medida um elemento fundamental para essa nova compreensão. Para um melhor entendimento acerca do tema, Iván López (2014, p. 265) pontua que:

O conceito de justiça ambiental questiona, assim, os fundamentos da política ambiental e social, de várias maneiras. Por um lado, redefinir o ambientalismo, integrando-o em maior medida com as necessidades sociais e humanas; por outro lado, questionando as posições ecocêntricas, bem como o desenvolvimento econômico de um corte capitalista que produza o impacto ambiental; e também, desafiando os fundamentos, o método científico e o paradigma positivista da comunidade científica. ${ }^{?}$

Como exemplo da aproximação governamental de perspectivas críticas, pontua-se também a conceituação difundida pela Agência de Proteção Ambiental dos Estados Unidos ${ }^{8}$ (EPA, 2019):

A justiça ambiental (JA) é o tratamento justo e o envolvimento significativo de todas as pessoas, independentemente de raça, cor, nacionalidade ou renda, com relação ao desenvolvimento, implementação e cumprimento de leis, regulamentos e políticas

7 Texto original: "El concepto de justicia ambiental cuestiona así las bases de la política medioambiental y social, de varias maneras. Por una parte, redefiniendo el medioambientalismo al integrarlo en mayor medida con las necesidades sociales y humanas; por otra parte, cuestionando las posiciones eco-céntricas al igual que el desarrollo económico de corte capitalista productor del impacto medioambiental; e igualmente, retando los fundamentos, el método científico y del paradigma positivista de la comunidad científica".

8 A Agência de Proteção Ambiental dos Estados Unidos é uma agência federal do governo dos Estados Unidos da América, encarregada de proteger a saúde humana e o meio ambiente: ar, água e terra. A EPA começou a funcionar em 2 de dezembro de 1970, quando foi instituída pelo presidente Richard Nixon. 
ambientais. Tratamento justo significa que nenhum grupo de pessoas deve ter uma parcela desproporcional das consequências ambientais negativas resultantes de operações ou políticas industriais, governamentais e comerciais. ${ }^{9}$

Ainda reforçando a convergência necessária entre sustentabilidade e justiça ambiental, sob a perspectiva da sociedade do risco, Ulrich Beck (2010, p. 23) esclarece que:

[...] a produção social de riqueza é acompanhada sistematicamente pela produção social de riscos. Consequentemente, aos problemas e conflitos distributivos da sociedade da escassez sobrepõem-se os problemas e conflitos surgidos a partir da produção, definição e distribuição de riscos científico-tecnologicamente produzidos.

À título de exemplo, pode-se citar o desabamento de um prédio ${ }^{10}$ ocupado no centro da cidade de São Paulo: uma grave e triste tragédia urbanística que reflete a falta de um planejamento socioambiental de um Estado falido que não cumpre sua função social. Pois, em vista dos conceitos acima debatidos, é um nítido exemplo de descompromisso com a justiça ambiental, onde o Estado busca a todo momento se eximir da responsabilidade e do compromisso para com as parcelas mais necessitadas da sociedade. Demonstrando, ademais, um entendimento restrito e limitado de sustentabilidade, que não atende às comunidades carentes de serviços socioambientais.

Com base nos estudos de Kempfer (2011) e Clodomiro José Bannwart Júnior (2012), em âmbito global, o Estado Moderno não se mostrou capaz de efetivar políticas públicas que garantissem a segurança humana. Nesse sentido, as empresas, enquanto instituições sociais, devem buscar interesses convergentes com os do Estado no sentido de efetivarem políticas de proteção e garantia aos direitos humanos. Devem buscar desenvolver benefícios socioculturais em detrimento dos prejuízos decorrentes da exploração econômica, que é altamente agressiva e degradante às diversas formas de meio ambiente e cultura. Assim, quando as empresas cumprem seu papel comunitário, satisfazem seu dever de responsabilidade social.

9 Texto original: "Environmental justice (EJ) is the fair treatment and meaningful involvement of all people regardless of race, color, national origin, or income with respect to the development, implementation and enforcement of environmental laws, regulations and policies. Fair treatment means no group of people should bear a disproportionate share of the negative environmental consequences resulting from industrial, governmental and commercial operations or policies".

10 A notícia do desabamento é de domínio público e pode ser encontrada em diversos canais de comunicação. Em matéria datada de 25 de julho de 2018, a revista Carta Capital destacou as características da tragédia: https://www.cartacapital.com.br/sociedade/apos-incendio-predioocupado-no-centro-de-sao-paulo-desaba/. 
Corroborando esse entendimento, Clodomiro José Bannwart Júnior (2017, p. 40) coloca que:

[...] é possível constatar que frente ao processo de conscientização da finitude dos recursos naturais e dos impactos ambientais na atividade produtiva, as empresas têm sido responsabilizadas e cada vez mais cobradas pela forma como interagem com o meio ambiente. Estão, pois, na linha de frente para responderem aos desafios do desenvolvimento sustentável.

Indo mais a fundo nessa discussão, é imprescindível que se faça uma breve reconstrução histórico-filosófica a respeito dos modelos estatais, para que se tenha uma compreensão crítica do potencial da interferência capitalista no ecossistema.

Resgatando o liberalismo clássico, de Adam Smith e John Locke como maiores expoentes, Clodomiro José Bannwart Júnior (2012) afirma que este modelo não foi capaz garantir as condições sociais adequadas e esperadas pelo homem. Comenta que o progresso pelo progresso foi responsável pela queda da qualidade de vida, exploração do trabalhador e intensificação dos problemas ambientais.

Para Locke o direito à propriedade, natural e inalienável, representava a liberdade máxima dos homens e a solução dos problemas de natureza. Enquanto isso, para Rousseau representava a própria violência e desigualdade da sociedade civil. Para este último filósofo, o liberalismo jamais poderia solucionar os problemas e as angústias do homem, jamais traria a tão prometida liberdade, pois não poderia caminhar com a justiça e com a igualdade. Deveria, portanto, ser substituído por um modelo de sobreposição da vontade geral sobre a individual, da justiça social sobre os interesses privados (WEFFORT, 2006).

Em um modelo de bem-estar social, pós-Segunda Guerra, o Estado encontra espaço para uma intervenção positiva que atue no sentido de amenizar as transformações sociais e ambientais da sociedade pós-industrial. No entanto, com a consolidação de um capitalismo mundializado e financeiramente vinculante, na era neoliberal, tem-se observado o interessante fenômeno da relativização e até perda da soberania estatal, o que afeta certamente a capacidade dos países de lidar com os problemas ambientais.

Como reflexo da reorganização do Estado, retomando Loureiro e Layrargues (2013), os movimentos e as lutas, agora minimizados, dão lugar ao discurso do consenso e do diálogo, das práticas conciliatórias, as quais os autores tecem uma dura crítica, principalmente quanto às 
maneiras de diálogo e aproximação que se tenta fazer hoje, um consenso de contrassenso:

Da explicitação dos conflitos como condição para a democratização passa-se à lógica do consenso e do diálogo, como se a desigualdade e o antagonismo de interesses de classe tivessem acabado ou como se a comunicação entre agentes sociais levasse ao consenso e à emancipação (LOUREIRO; LAYRARGUES, 2013, p. 59).

Ou seja, critica-se a escola ambiental tradicional que tenta de forma ilusória sanar os problemas ambientais a partir de um discurso amigável com a lógica do capital. Seguem, os autores, dizendo que a expansão do capital, por encontrar limites na natureza, vai sobrepô-la para alcançar seus objetivos e metas. Evidencia-se, então, a necessidade de combater efetivamente esses problemas socioambientais.

Nesse aspecto, concordam Loureiro e Layrargues (2013), autores de viés crítico-marxista, que a solução para a verdadeira efetivação de uma sustentabilidade social e ambiental é a extinção do modo de produção capitalista, altamente degradante e manipulador das relações político-estatais. Segundo os autores, não há qualquer possibilidade de diálogo entre aspirações sustentáveis e a lógica de produção capitalista.

Diante de uma agressiva globalização cultural, social e sobretudo econômica, os Estados nacionais e o meio ambiente se veem como reféns das grandes corporações e empresas transnacionais e multinacionais, que, além de concentrarem maior poderio financeiro e de influência política que muitos países, ditam os rumos e as necessidades da globalização sob a ilusão de levar desenvolvimento tecnológico, empregabilidade e autonomia estatal.

Em que pese concordar-se em grande parte com Loureiro e Layrargues, entende-se que é necessário estabelecer um diálogo entre a globalização empresarial e o meio ambiente no sentido de refletir acerca dessa enigmática relação. Esse embate perpassa, no cenário global, pela crise dos Estados Nacionais, sendo necessário desenvolver um tópico a respeito dessa relação - que se faz a seguir.

\section{MEIO AMBIENTE, GLOBALIZAÇÃO E CRISE DO ESTADO NACIONAL}

No debate acerca da crise dos Estados Nacionais, Luigi Ferrajoli (2002) questiona-se a respeito da viabilidade de uma democracia sem 
Estado, haja vista alguns autores apontarem para o seu desaparecimento em face dos novos poderes econômicos transnacionais e multinacionais.

A resposta parece negativa. A democracia e com ela a defesa do meio ambiente dependem de um Estado que seja capaz de ditar os próprios rumos, que seja capaz de não ceder a pressões externas e contrárias aos interesses internos de cada país. Diante do surgimento dos poderes transnacionais, caracterizados pelo déficit de democracia, Ferrajoli (2002) diz que é preciso repensar o Estado e a própria ordem internacional. Um depende do outro, e não deve se sobrepor ao outro.

Para que se possa pensar um diálogo entre o poder econômico transnacional e os Estados é preciso que um tenha o tamanho do outro, sob pena desse diálogo continuar sendo um monólogo do regime capitalista. Os Estados-nação devem se organizar em instituições supranacionais, capazes de regulamentar, pressionar e sancionar as grandes corporações e setores da economia global. Ferrajoli (2002) chama atenção, ainda, para o fato de não haver no plano internacional uma instituição capaz de domesticar esses poderes globais, não há, na esfera pública, uma organização que atue na defesa dos interesses gerais como a paz, a segurança, o meio ambiente, a sustentabilidade e os direitos fundamentais de forma efetiva. É justamente essa lacuna, esse vácuo, que leva o autor a aferir um vazio do direito público internacional.

O capitalismo global interfere diretamente na capacidade de sustentabilidade. Sob pressão, os estados nacionais são obrigados a aceitar a livre circulação das empresas multinacionais e transnacionais, que procuram mão-de-obra barata, legislação trabalhista frágil e Estados incapazes de medir ou punibilizar adequadamente os danos socioambientais - poluição dos ecossistemas; descaracterização da cultura local; aumento da criminalidade, prostituição, uso de álcool e drogas; a própria exploração do trabalhador; entre outros.

Contrapõe-se a essa ideia a autora Cristiane Derani (2008), que afirma serem indissociáveis os fundamentos econômicos de uma política ambiental. Para administrar a produção econômica, diz a autora, não se pode desvaler de uma política de proteção do meio ambiente e dos recursos naturais. $\mathrm{O}$ que se pretende com isso é a justa conciliação que permita, com auxílio do direito, manter a ordem de desenvolvimento capitalista atual com um uso racional e consciente dos recursos e da natureza, fundamentais nesse processo.

$\mathrm{O}$ direito ambiental nasce do dilema progresso industrial versus 
proteção ao meio ambiente, como uma lei que tenta amenizar esse conflito. Continua a autora dizendo que os riscos trazidos pela ideia de desenvolvimento industrial criam uma perspectiva de danos irreversíveis e, consequentemente, a necessidade de pensar como evitá-los.

Entende-se, no entanto, que há uma espécie de contradição no modo de ver de Cristiane Derani (2008). Tendo em vista os danos ao meio ambiente, muitas vezes irreparáveis, que o capitalismo industrial cria e tem criado há muitas décadas, é possível argumentar que essa aliança, nos termos atuais, pode não gerar bons frutos.

Ademais, a lei não funciona como disse Derani (2008), como um consenso visando assegurar em última análise a qualidade de vida das pessoas - que é uma preocupação tanto do direito econômico quanto do ambiental. Mas sim, como o mínimo de proteção possível, dentro da lógica exploratória. Em verdade, o Direito Ambiental, refém do setor econômico, chega até onde a confluência de interesses econômicos, políticos e sociais do Estado permite que ele chegue.

Diante desse cenário, a possibilidade pensada por Ferrajoli (2002) consiste na reformulação, ou mesmo criação, de instituições globais que possam efetivamente garantir a proteção aos direitos fundamentais, protegendo o ambiente interno de cada Estado contra os efeitos da globalização. Essas organizações supranacionais devem possuir a força e os instrumentos necessários para pressionar, sancionar e obrigar os Estados e os poderes econômicos transnacionais a cumprirem seus direcionamentos.

Essa solução pode representar um preenchimento da lacuna do direito público internacional a que se refere Ferrajoli (2002). Esse vazio pode ser constatado, na atualidade, por exemplo, nos recentes episódios bélico-nucleares da Coreia do Norte: há anos afrontando o mundo sem que absolutamente nenhum organismo pudesse efetivamente coagi-la a parar, sendo que, somente quando a Coreia decidiu por si própria é que tomou rumo diplomático.

O mesmo alerta vale para os Estados Unidos, que rejeitam pactos ambientais anteriormente assumidos enão se submetem aos direcionamentos e ajustes da Organização das Nações Unidas (ONU) no sentido de não assumir pactos globais de cooperação e responsabilização universal, a exemplo da saída do Acordo de Paris (PRESIDENT TRUMP..., 2017) sobre as mudanças climáticas, do Acordo Nuclear Iraniano (PRESIDENT DONALD J. TRUMP IS ENDING..., 2018) e da suspensão ao Tratado de Forças Nucleares Intermediárias (PRESIDENT DONALD J. TRUMP TO 
WITHDRAW..., 2019) com a Rússia - este último sob o argumento de que a Rússia estaria descumprindo-o.

Isso tudo demonstra que ainda há um longo caminho a percorrer. O meio ambiente, a democracia e a própria humanidade vivem sob risco iminente. Não há, como notou Ferrajoli (2002), uma segurança internacional definitiva e confiável. Nem mesmo Kant (2008), no século XVIII, imaginaria que ainda no século XXI não se teria atingido a tão esperada paz perpétua. $O$ filósofo, já em sua época, sinalizava a importância dos caminhos internacionais diplomáticos, bem como da necessidade de um tipo de código global de leis, com os artigos definitivos que levariam à paz.

Resta, entretanto, discutir novas possibilidades que poderiam contribuir para assegurar o mínimo de segurança e paz tanto aos homens como ao meio ambiente.

\section{O ESTADO SOCIOAMBIENTAL E A IDEIA DE BEM VIVER INTEGRADA À SUSTENTABILIDADE}

Diante das crises aventadas nos capítulos anteriores, Ayala e Rodrigues (2013) criticam o fato do conceito ocidental dominante de sustentabilidade possuir uma abordagem antropocêntrica, no sentido de que algo só é protegido pela aura sustentável quando tem alguma utilidade para o ser humano. Acertando essa crítica no campo do direito brasileiro, continuam os autores:

[...] no que se refere ao ordenamento jurídico-constitucional brasileiro, mesmo considerando um princípio de sustentabilidade [...] entende-se que os níveis de proteção ao meio ambiente que daí resultam são insuficientes, por serem incapazes de contemplar a proteção da vida em geral, e de minorias culturalmente diversas, como os povos indígenas (AYALA; RODRIGUES, 2013, p. 318).

Diante dessa posição, a proteção ao meio ambiente não é garantida porque o entendimento que se tem sobre o princípio da sustentabilidade não aborda a complexidade ecológica pelo viés da diversidade cultural. Afirmam os autores que "a ideia de sustentabilidade precisa interagir com experiências culturais não ocidentais, para que possam ser viabilizados projetos de vida dignos, comprometidos com toda a comunidade, de uma maneira integral e duradoura" (AYALA; RODRIGUES, 2013, p. 318).

Ayala e Rodrigues (2013) continuam dizendo que o Estado de Direito é quem deve dar respostas aos problemas e às crises vivenciadas, devendo 
oferecer proteção à vida e à dignidade de forma completa. No entanto, para os autores, a concepção do Estado de Direito que se tem atualmente é insuficiente para enfrentar a gama de crises e riscos globais. Com isso, sugerem a adoção de um Estado Socioambiental de Direito, cuja ideia é:

[...] agregar em um mesmo projeto político-jurídico as conquistas do Estado Liberal e do Estado Social, em termos de tutela da dignidade, incorporando ainda as exigências e valores vinculados ao Estado Socioambiental de Direito, a fim de alcançar o objetivo maior do Estado, qual seja, o desenvolvimento da vida, e a garantia de sua perpetuação no tempo (AYALA; RODRIGUES, 2013, p. 319).

Assim, essa nova configuração do Estado pode conferir maior amparo às questões ambientais e humanitárias, uma vez que os deveres de proteção vinculariam os poderes estatais. Haveria também uma limitação da margem de discricionariedade do Estado no âmbito da escolha das medidas protetivas do meio ambiente, "Afinal, o Estado Socioambiental tem um papel ativo para promover os direitos fundamentais, especialmente no que tange à tutela ambiental" (AYALA; RODRIGUES, 2013, p. 320).

Dentro da ideia desse novo modelo de Estado, os autores propõem um diálogo cultural com povos originários latino-americanos que possa "favorecer uma proteção reforçada ao meio ambiente, construída a partir de um sentido de integração e equilíbrio, e de alargamento de valores essenciais, como a própria dignidade" (AYALA; RODRIGUES, 2013, p. 321).

Aí encontra-se, segundo os autores, o ideal de bem viver, que consiste em "um verdadeiro projeto existencial, coletivamente construído, que exige, portanto, uma quebra de paradigmas em relação a categorias tradicionais do Direito ocidental em favor da construção de uma sociedade pluralista, fundada na harmonia e no respeito à vida" (AYALA; RODRIGUES, 2013, p. 324).

Sob esse enfoque, sustenta-se que é necessário integrar ao conceito de sustentabilidade a ideia de bem-viver. Essa ideia, que foi resgatada pela terceira onda do movimento constitucionalista latino-americano, tem como característica um olhar pela diversidade cultural, cujo objetivo é proporcionar mecanismos constitucionais efetivos de respeito integral às diversas culturas e povos e sua relação com os respectivos ecossistemas - em especial o respeito e a proteção aos povos de origem indígena e de suas tradições, costumes, entendimento de mundo e de desenvolvimento, inclusive a partir de jurisdição e tribunais indígenas, a exemplo do caso Boliviano. 
Esse novo constitucionalismo, ou constitucionalismo andino, representa a elevação da diversidade e da pluralidade cultural a níveis constitucionais, marcando a construção de uma identidade própria dos países latino americanos fundada em respeito, dignidade, interculturalidade e historicidade. Wolkmer (2010) divide o movimento em três ciclos: (1) social e descentralizador - Constituições do Brasil em 1988 e da Colômbia em 1991; (2) participativo e pluralista - Constituição Venezuelana de 1999. E, por fim, o ciclo (3) plurinacional comunitário - marcado pelas Constituições do Equador e da Bolívia, em 2008 e 2009.

Para Fernanda Bragato e Natalia Castilho (2014, p. 11-12), no contexto da América-Latina, o novo movimento:

[...] tem representado algumas mudanças, avanços e rupturas com o modelo constitucional de matriz europeia e norte-americana que, via de regra, serviram de modelo teórico para as Constituições desses países desde suas respectivas independências. [...] ostenta características descolonizadoras, com o reconhecimento da cosmovisão indígena e com um novo projeto societário, que busca incluir sujeitos e coletivos historicamente excluídos e marginalizados, especialmente os indígenas, as mulheres e os campesinos.

O constitucionalismo latino-americano, em seu terceiro ciclo, marca finalmente a ruptura com os paradigmas ocidentais do constitucionalismo tradicional, ou colonizador. É um ato de liberdade e de bravura. Como sugere a obra de Eduado Val e Enzo Bello (2014), representa um pensamento descolonial, uma refundação do Estado sob um novo olhar, construído a partir dos mais diversos grupos sociais, históricos e culturalmente fundantes de cada país.

Esse movimento consubstanciou o bem viver nas constituições do Equador (2008) e da Bolívia (2009), oficializando o plurinacionalismo, os direitos de bem viver, e os direitos da natureza.

Nos dizeres de Wolkmer (2001, p. 171), para fins de conceituação, o marco teórico do Pluralismo significa "a existência de mais de uma realidade, de múltiplas formas de ação prática e da diversidade de campos sociais ou culturais com particularidade própria, ou seja, envolve o conjunto de fenômenos autônomos e elementos heterogêneos que não se reduzem entre si".

A constituição do Equador, no art. $1^{\circ}$, define como elemento constitutivo do Estado o plurinacionalismo. Concede ainda, por exemplo, os seguintes direitos relacionados ao bem viver: "à água e alimentação, a um ambiente sadio, à comunicação e informação, à cultura e ciência, à 
educação, ao habitat e moradia, à saúde, ao trabalho e à seguridade social". E ainda dentro do título "regime do bem viver" (Regimen Del Buen Vivir), os capítulos: "inclusão e equidade" e "biodiversidade e recursos naturais" (Constituição do Equador, 2008).

Nota-se que a ideia de bem viver tem uma acepção de integração e equilíbrio, buscando, na origem humana, o respeito às mais diversas formas de vida e cultura, tendo uma compreensão de homem e natureza como um só.

Assim, a ressignificação da sustentabilidade para que seja integrada à ideia de bem viver representa, de certa forma, uma possibilidade de proteção e garantia da dignidade humana sob uma perspectiva plural e coletiva, com a participação ativa do Estado Socioambiental e da sociedade, servindo de auxílio às respostas para as crises vivenciadas na modernidade.

A constituição nos moldes tradicionais não responde mais às expectativas e demandas sociais. O novo entendimento pressupõe não uma carta-catálogo de direitos fundamentais e deveres escritos, mas sim uma verdadeira força normativa de interação, que compreenda a profundidade das transformações sociais, do resgate cultural, bem como do cumprimento inequívoco dos princípios democráticos.

\section{CONCLUSÃO}

A integração dos conceitos de sustentabilidade e bem-viver não significa tão somente uma transformação no âmbito da linguagem e da gramática, mas sim uma propulsão da própria reflexão acerca de um Estado Socioambiental de Direito.

Diante das ideias aqui tratadas, propõe-se um diálogo entre as forças econômicas capitalistas, os negócios jurídicos e o meio ambiente. Contudo, um diálogo em condições mais igualitárias de debate. A fim de que essa conversa seja possível, entende-se necessária a instituição de um Estado Socioambiental que promova a inversão de valores sociais, protagonizando em primeiro plano o ser humano, a dignidade, a pluralidade cultural e o meio ambiente em detrimento do materialismo e da racionalidade econômica.

O Direito Negocial se conecta intrinsecamente ao atual estágio do Estado contemporâneo na medida em que os negócios jurídicos, regulados pela autonomia privada, derivam, indiretamente, da capacidade de controle interno, força e influência política dos Estados.

$\mathrm{O}$ direito econômico, enquanto política econômica, tem condão para 
constituir novas normas jurídicas e vice-versa. Há uma relação dialética entre o direito econômico e a norma jurídica. Neste aspecto, o primeiro não pode reduzir-se à mera instrumentalidade da economia, não pode, nas palavras de Cristiane Derani (2008, p. 41), "renunciar à realização da ideia de justiça e, consequentemente, a influir na conformação das relações sociais, neste caso da ordenação da economia". Nesse sentido entende-se a teoria do direito econômico pelo seu aspecto mais amplo, que não se refere meramente à elaboração e circulação de bens, mas sim à toda produção da vida econômica e da vida social, portanto.

A realidade social é intrínseca à análise do direito econômico, é parte essencial de sua formação, não se pode, pois, ignorar essa interação. Sendo a finalidade do direito a paz social, a busca por um desenvolvimento completo das sociedades, tanto social quanto ambiental, torna-se imprescindível e, decorrente disso, a necessária regulação e proteção destes, o que envolve o direito ambiental.

Destaca-se, com base em Derani (2008), a dupla dimensão do direito econômico: de um lado como protetor da busca pelo bem-comum e, de outro, como garantidor da iniciativa privada. Falar em direito econômico é trabalhar com a questão do lucro, da produtividade e, por isso, as normas a ele referentes devem possuir capacidade de adaptação conjuntural a fim de não perder de vista o foco no desenvolvimento do bem-comum. Tem-se que, em verdade, o direito deve fornecer as condições para o desenvolvimento socioambiental.

Os negócios jurídicos, sob a perspectiva da autonomia privada e do Estado Socioambiental, devem tutelar efetivamente a proteção aos direitos humanos sob o enfoque da sustentabilidade.

Assim, conclui-se que o sistema capitalista não é contraditório ao desenvolvimento ambiental, mas deve, no entanto, ser posicionado em segundo plano, controlado e submisso às forças e de um novo Estado. Seu protagonismo deve ser aquele de construção das relações comerciais e de troca em consonância com os objetivos socioambientais e sustentáveis.

O direito ambiental não pode ser tratado, dizem Ana Carla Freitas e Gina Vidal Pompeu (2019), como instrumento de mera encenação simbólica no combate ao inimigo chamado de tragédias ambientais e concretizado na estrutura de "irresponsabilidade organizada".

Por derradeiro, tem-se que a necessidade de construção conceitual do Estado Socioambiental de Direito mostra-se de vital importância diante das atuais crises do mundo em transformação e das pressões executadas 
pelos poderes capitalistas transnacionais. Também essencial é a aliança da ideia de bem viver ao princípio da sustentabilidade, como forma de corroborar esse conceito a fim de que ele possa servir de resposta às crises do Estado contemporâneo.

\section{REFERÊNCIAS}

ACSELRAD, H. Ambientalização das lutas sociais - o caso do movimento por justiça ambiental. Estudos Avançados, São Paulo, v. 24, n. 68, p. 103 -119, 2010. Disponível em: http://www.scielo.br/scielo.php?script=sci arttext\&pid=S0103-40142010000100010\&lng=en\&nrm=iso. Acesso: 12 mar. 2019.

ACSELRAD, H.; HERCULANO, S.; PÁDUA, J. A. A justiça ambiental e a dinâmica das lutas socioambientais no Brasil: uma introdução. In: ACSELRAD, H.; HERCULANO, S.; PÁDUA, J. A. (orgs.). Justiça ambiental e cidadania. Rio de Janeiro: Relume Dumará, 2004.

AYALA, P. A.; RODRIGUES, E. M. W. Diálogo intercultural e proteção do meio ambiente: por um princípio de sustentabilidade integrado pela ideia de bem viver. In: CONGRESSO BRASILEIRO DE DIREITO AMBIENTAL, 18., 2013, São Paulo. Anais (online) v. 2. São Paulo: Planeta Verde, 2013. p. 316-326. Disponível em: http://www.planetaverde. org/arquivos/biblioteca/arquivo_20131201045021_6976.pdf. Acesso em: 30 abr. 2018.

BANNWART JÚNIOR, C. J. Globalização, empresa e responsabilidade social. In: II SEMINÁRIO INTERNACIONAL DE HISTÓRIA E DIREITO: INSTITUIÇÕES POLÍTICAS, PODER E JUSTIÇA, 2., 2012, Rio de Janeiro. Scientia Iuridica - Tomo LXI, 2012. n. 330. Rio de janeiro: Scientia iuridica, 2012. p. 579-596.

- Responsabilidade integral - pedagogia da responsabilidade integral. In: _. et al. Responsabilidade integral, metodologia estratégica para o desenvolvimento pessoal, corporativo e educacional. Londrina: Midiograf, 2017.

BECK, U. Sociedade de risco: rumo a uma outra modernidade. São Paulo: 34, 2010. 
BRAGATO, F. F.; CASTILHO, N. M. A importância do pós-colonialismo e dos estudos descoloniais na análise do novo constitucionalismo latinoamericano. In: VAL, E. M.; BELLO, E. (orgs.). O pensamento pós e descolonial no novo constitucionalismo latino-americano. Caxias do Sul: Educs, 2014. p. 11-25.

BRASIL. [Constituição (1988)]. Constituição da República Federativa do Brasil. Brasília, DF: Senado Federal, 1988.

CANOTILHO, J. J. G. Direito constitucional e teoria da constituição. 7. ed. Coimbra: Livraria Almeida, 2003.

DERANI, C. Direito ambiental econômico. 3. ed. São Paulo: Saraiva, 2008.

DOVERS, S. R. Sustainability: demands on policy. Journal of Public Policy, v. 16, n. 3, p. 303-318, 1996.

ELKINGTON, J. Towards the sustainable corporation: win-win-win business strategies for sustainable development. California Management Review, v. 36, n. 2, p. 90-100, 1994. Disponível em: https://doi. org/10.2307/41165746. Acesso em: 5 jan. 2019.

EPA - UNITED STATES ENVIRONMENTAL PROTECTION AGENCY. Learn about environmental justice. Disponível em: https:/www.epa.gov/ environmentaljustice/learn-about-environmental-justice. Acesso em: jan. 2019.

FACHIN, L. E. Teoria crítica do direito civil. 3. ed. Rio de Janeiro: Renovar, 2012.

FERRAJOLI, L. A soberania no mundo moderno: nascimento e crise do Estado nacional. São Paulo: Martins Fontes, 2002.

FREITAS, A. C. P.; POMPEU, G. V. A função simbólica do direito ambiental: considerações sobre o tema 30 anos depois da constituição de 1988. Veredas do Direito - Direito Ambiental e Desenvolvimento Sustentável, Belo Horizonte, v. 16, n. 34, p. 235-252, jan./abr. 2019. Disponível em: http://www.domhelder.edu.br/revista/index.php/veredas/ article/view/1328. Acesso em: 16 ago. 2019.

GRAU, E. R. A ordem econômica na constituição 1988. 14. ed. rev. e atual. São Paulo: Malheiros, 2010. 
KANT, I. À paz perpétua. Porto Alegre: L\&PM, 2008.

KEMPFER, M. Segurança humana e o dever jurídico das empresas brasileiras. In: .; BELLINETTI, L. F. (orgs.). Estudos em direito negocial. Curitiba: CRV, 2011. p. 193-220.

LÓPEZ, I. E. Justicia ambiental. Revista en Cultura de la Legalidad, n. 6, p. 261-268, mar./ago. 2014. Disponível em: https://e-revistas.uc3m.es/ index.php/EUNOM/article/view/2194/1130. Acesso em: 5 jan. 2019.

LOUREIRO, C. F. B.; LAYRARGUES, P. P. Ecologia política, justiça e educação ambiental crítica: perspectivas de aliança contra-hegemônica. Trab. Educ. Saúde, Rio de Janeiro, v. 11, n. 1, p. 53-71, jan./abr. 2013.

PRESIDENT DONALD J. TRUMP IS ENDING United States Participation in an Unacceptable Iran Deal. The White House, 8 maio 2018. Disponível em: https://www.whitehouse.gov/briefings-statements/president-donald-jtrump-ending-united-states-participation-unacceptable-iran-deal/. Acesso em: 11 mar. 2020.

PRESIDENT DONALD J. TRUMP TO WITHDRAW the United States from the Intermediate-Range Nuclear Forces (INF) Treaty. The White House, 1 fev. 2019. Disponível em: https://www.whitehouse.gov/ briefings-statements/president-donald-j-trump-withdraw-united-statesintermediate-range-nuclear-forces-inf-treaty/. Acesso em: 11 mar. 2020.

PRESIDENT TRUMP Announces U.S. Withdrawal From the Paris Climate Accord. The White House, 1 jun. 2017. Disponível em: https://www. whitehouse.gov/articles/president-trump-announces-u-s-withdrawalparis-climate-accord/. Acesso em: 11 mar. 2020.

TRIPLE bottom line. The Economist, 17 nov. 2009. Disponível em: https:// www.economist.com/news/2009/11/17/triple-bottom-line. Acesso em: 9 jul. 2018.

VAL, E. M.; BELLO, E. (orgs.). O pensamento pós e descolonial no novo constitucionalismo latino-americano. Caxias do Sul: Educs, 2014.

WEFFORT, F. C. (org.). Os clássicos da política. v. 1. 14. ed. São Paulo: Ática, 2006.

WOLKMER, A. C. Pluralismo jurídico: fundamentos de uma nova cultura no Direito. 3. ed. São Paulo: Alfa-Omega, 2001. 
. Pluralismo e crítica do constitucionalismo na América Latina.

In: Anais do IX Simpósio Nacional de Direito Constitucional. Curitiba: Academia Brasileira de Direito Constitucional, 2010.

WWF - WORLD WILDLIFE FUND. Pegada Ecológica? O que é isso? Disponível em: https:/www.wwf.org.br/natureza_brasileira/especiais/ pegada_ecologica/o_que_e_pegada_ecologica/. Acesso em: 9 jul. 2018.

Artigo recebido em: 18/06/2019. Artigo aceito em: 04/03/2020.

\section{Como citar este artigo (ABNT):}

ARAUJO JUNIOR, M. E.; MARTINS, L. G. C. Indivíduo, sociedade e direitos humanos: a sustentabilidade integrada à ideia de bem viver e sua relação com os negócios jurídicos no mundo globalizado. Veredas do Direito, Belo Horizonte, v. 17, n. 37, p. 169-190, jan.-abr. 2020. Disponível em: http://revista.domhelder.edu.br/index.php/veredas/article/view/1566. Acesso em: dia mês. ano. 